\title{
Clinical treatment of advanced synchronous triple primary malignancies: comprehensive treatment based on targeted therapy
}

This article was published in the following Dove Press journal: OncoTargets and Therapy

\section{Ying Zhang \\ Yunjie Ge \\ Xiaohui Wu \\ Shuangmei Liu}

Department of Internal Medicine, Municipal Hospital, Qingdao, Shandong, People's Republic of China
Correspondence: Shuangmei Liu Department of Internal Medicine, Qingdao Municipal Hospital, 5 Donghai Middle Road, Qingdao, Shandong,

People's Republic of China

Tel +861 7685552026

Email shuangmei2008@I26.com

\begin{abstract}
The prevalence of cancer remains high. With the improvement of diagnosis and treatment level and the increase of cancer survivors after treatment, multiple primary tumors are more common than before. The diagnosis and treatment of synchronous multiple primary tumors is more complicated than that of single or metachronous multiple tumors, and patients also suffer more. Because of the different conditions of these patients, lack of large-scale clinical observation data, it is necessary for clinicians to make realistic decisions on the specific conditions of patients. It is a challenge for clinicians to apply the advances of modern medicine to the diagnosis and treatment of such patients so as to prolong their survival time and improve their quality of life. This report describes the survival of an advanced elderly patient with lung, prostate and bladder cancer after receiving targeted therapy-based comprehensive treatment.
\end{abstract}

Keywords: advanced synchronous triple primary malignancies

\section{Introduction}

In recent years, due to the improvement in screening methods, early intervention, diagnostic sensitivities and therapy ways, the prevention, diagnosis and treatment of cancer patients have made great advances, so that the overall survival time and quality of life of cancer patients have made significant progress. ${ }^{1,2}$ This improvement and aging of the population have led to a surge in the number of survivors of secondary multiple tumors, which poses an additional threat in terms of morbidity and mortality. ${ }^{3,4}$ Compared with the general population, cancer survivors had a $14 \%$ increased risk of developing a second primary cancer. ${ }^{5-7}$

The incidence of multiple primary cancers ranged from $2.4 \%$ to $8 \%$, with a maximum of $17 \%$ within 20 years of follow-up. ${ }^{1}$ Compared with synchronous primary cancer $(59 \%)$ and single primary cancer $(59 \%)$, metachronous cancer (95\%), simultaneous concomitant multiple primary tumors had the lowest 5-year survival rate, averaging 1.9 years. ${ }^{3}$ Most studies have shown that the prognosis of synchronous primary cancer patients is worse than that of metachronous primary patients. ${ }^{8,9}$ Multiple primary cancers are often understood as simultaneous cancers or metachronous cancers that occur sequentially. ${ }^{10}$

Because of the different nature of multiple primary cancers, they should be treated as different tumors, including staging and treatment. ${ }^{11,12}$ These problems make the management of patients with multiple primary tumors continues to be 
a challenge. As some researchers have pointed out, although there are many studies on multiple tumors, the practical implications of managing multiple primary lesions are seldom discussed. ${ }^{13}$ In this report, we describe an advanced patient with simultaneous concomitant lung cancer, prostate cancer and bladder cancer who underwent targeted therapy combined with hormonal therapy and surgical treatment and survived for 1 year and 10 months.

This case is extremely rare because the simultaneous occurrence of lung cancer, prostate cancer and bladder cancer with bone metastasis has not been reported in the literature.

\section{Case report}

An 81-year-old man never-smoker was referred to our hospital due to cough, sputum and fever continuing for over 2 weeks on Sept 1, 2016. In all the patient's medical history, he had only suffered from hyperlipidemia and gallbladder stones, and had received surgical treatment for cervical dislocation 5 years ago. He denied previous diseases, including cancer or malignant tumors, and had never received any radiation or chemotherapy, and had never been exposed to any particular substance, such as arsenic. There are only occasional small amounts of alcohol in his life and no history of heavy drinking or alcoholism. Because of the distance of time and the poor medical conditions of many years ago, the patient was unable to account for the cause of death and illness of his parents and family members. Computed tomography (CT) of this patient's chest showed an abnormal mass shadow in his left lower lung, mediastinal lymph node enlargement. The serum concentration of the serum carcinoembryonic antigen (CEA) was $53.32 \mathrm{ng} / \mathrm{mL}$, and prostate specific antigen (PSA) was $>100 \mathrm{ng} / \mathrm{mL}$. Abnormal signal foci in the central region of prostate magnetic resonance imaging, the bladder is poorly filled, with several prominent shadow-like sacs on the left side wall. The whole body bone imaging examination showed abnormal bone metabolism, consistent with the signs of multiple bone metastases (Figure 1). The histopathologic findings revealed hypodifferentiated adenocarcinoma after a biopsy specimen obtained by fiber-optic bronchofiberscopy (Figure 2). After the same detailed understanding of the process of prostate puncture and cystoscopy, the painful experience of bronchoscopy made the patient firmly refuse further invasive examination, because both prostatic puncture and cystoscopy are invasive examination. According to the rules, the clinician must obtain the patient's consent for invasive examination, otherwise it can not be carried out.

Then, the EGFR mutation status of the specimens obtained by bronchoscopy was investigated, and the result showed both exon 19 deletions and an L858R point in exon 21. Then icotinib (125 mg) (patent number WO2003082830; Zhejiang Bata Pharma Ltd., Hangzhou, People's Republic of China) was orally administered three times a day after the result was EGFR mutation-positive.

The patient had mild diarrhea after taking icotinib, and obvious relief of cough and chest discomfort, so he did not follow the doctor's advice to review the chest CT until 3 months later. CT results showed a marked reduction in tumor size (Figure 3).

After 6 months, the patient came back to see the doctor again because the frequency of urination affected his nighttime sleep. The difference is that this time the patient is in good spirits and believes that the doctor can solve his discomfort in urination. The results of urological magnetic resonance imaging (MRI) examination showed irregular enlargement of prostate and abnormal signal (Figure 4), which considered prostate cancer, not excluding left seminal vesicle gland involvement, while the left bladder wall occupied space (Figure 5), pelvic lymph node enlargement. Echocardiographic display of pericardial effusion. The serum concentration of the serum CEA was $3.62 \mathrm{ng} / \mathrm{mL}$, and PSA was $>100 \mathrm{ng} / \mathrm{mL}$. The whole body bone imaging examination showed that abnormal bone metabolism was progressive. Urologists again recommend prostate puncture or cystoscopy. Patients refuse invasive examination, hoping to receive minimal suffering treatment according to the expected diagnosis.

Hormonal therapy is recommended in urology. Bicalutamide tablets (Casodex, AstraZeneca $\mathrm{GmbH}$ ) $50 \mathrm{mg}$ is taken orally once a day and Leuprorelin acetate microspheres sustained release for injection (Beijing Biote Pharmaceutical Co. Ltd) $3.75 \mathrm{mg}$ is given subcutaneously every 4 weeks, strontium dichloride for bone metastasis. Later, the patient's symptoms improved according to the doctor's instructions. The patient was not admitted to hospital until September 3, 2017 (4 months after receiving prostate treatment and 11 months after lung cancer targeted treatment) due to frequent urination and increased pain in the lower abdomen. Blood reexamination showed CEA $2.8 \mathrm{ng} / \mathrm{mL}$, PSA $1.18 \mathrm{ng} / \mathrm{mL}$, CT examination showed that the prostate gland is full, with uneven density and calcification, which is consistent with the changes after endocrine 

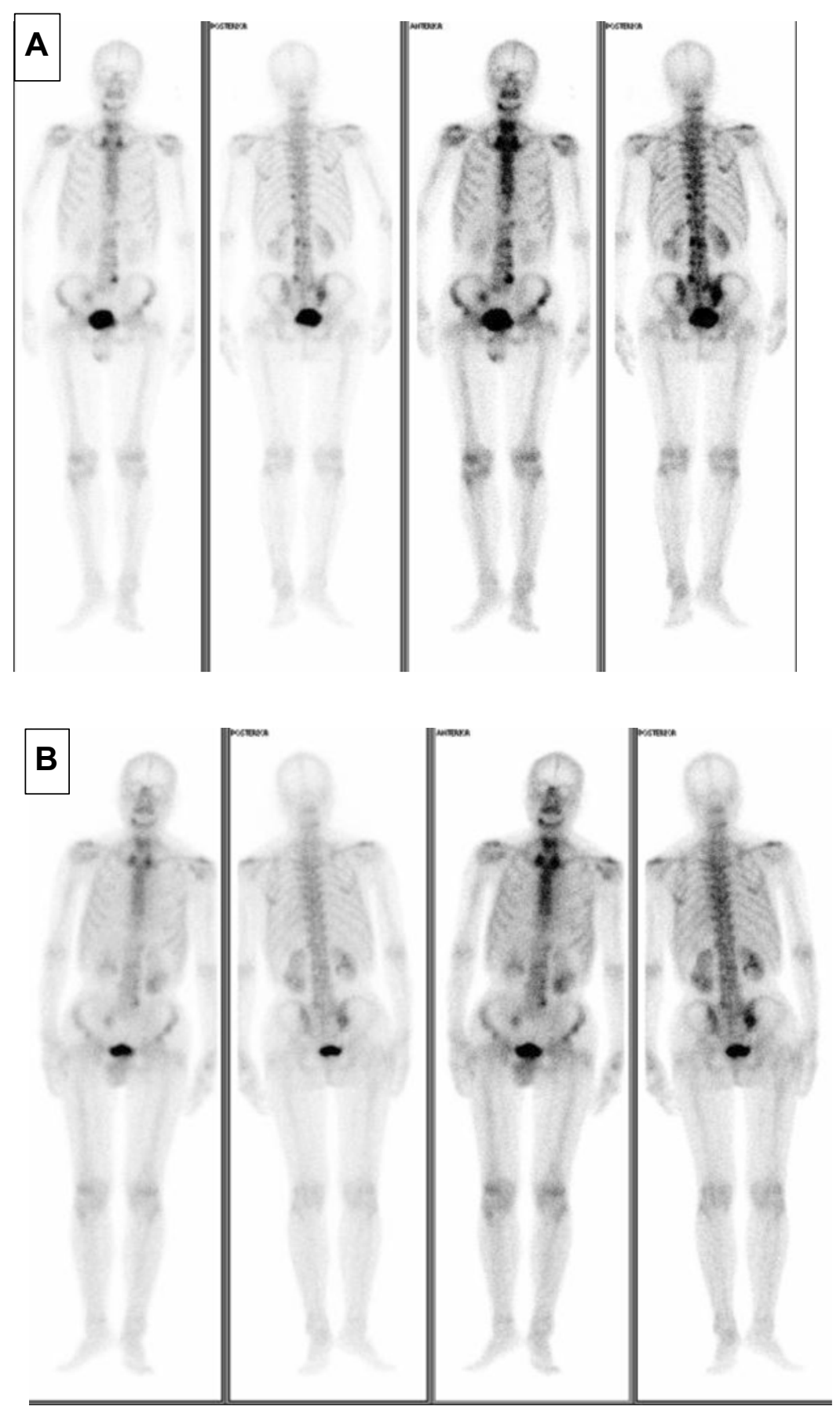

Figure I The whole body bone imaging examination. (A) Showed abnormal bone metabolism, consistent with the signs of multiple bone metastases: The right side of mandible, chest II, left side of lumbar 2 vertebra, left side of lumbar 4 vertebra pedicle, sacrum and right side of sacroiliac joint showed increased patchy radioactive uptake, and the right side of pyramidal 8 and 10 showed slightly increased reflective uptake. (B) Showed abnormal bone metabolism was significantly alleviated after 6 months of hormone therapy for prostate cancer.

therapy. The left side wall of the bladder is significantly irregularly thickened and involves the lower end of the left ureter, and the left renal pelvis and ureteral dilatation and hydrocele. CT also showed partial nodules decreased in both lungs (considering the metastasis of prostate cancer in the lungs) (Figure 6), new nodules appeared, and pericardial effusion did not change significantly. The whole body bone imaging examination showed abnormal bone metabolism was significantly alleviated (Figure 1). Then, the patient underwent transurethral electric resection of bladder lesions. Postoperative pathology showed invasive urothelial 


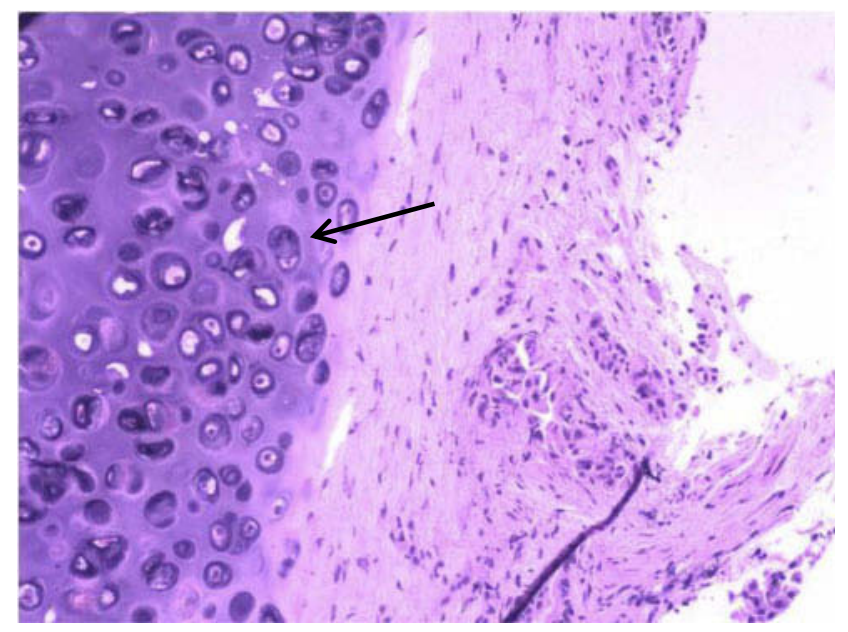

Figure 2 Hematoxylin-eosin-stained (10*20) biopsy specimens obtained by broncho berscopy. The tumor cells are large with highly atypical nuclei, and the histology and immunohistochemical findings suggest adenocarcinoma. Immunohistochemical results: TTF-I(+), CK7(+), P63(-), P40(-), NapsinA(+).

carcinoma (Figure 7). Nine days after surgery, the patient developed hematuria, bladder irrigation was given and catheterization was retained for 3 weeks. Targeted therapy for lung cancer and treatment for prostate cancer remained unchanged. On April 4, 2018, he was admitted to hospital again because of hematuria and urine urgency. Considering the diagnosis of recurrence of bladder cancer and the patient's intolerance to surgery, he was given bilateral internal iliac artery angiography plus superselective embolization, and gemcitabine 1,000 $\mathrm{mg}$ was applied during the operation. On May 16, 2018, the patient was admitted to the hospital again due to urination urgency, urination pain and fever for 2 days. After anti-infection and improvement of the general condition, the patient's symptoms improved. After that, the original treatment was maintained. On May 22, serum creatinine rose to $182.97 \mu \mathrm{mol} / \mathrm{L}$, and the patient refused further treatment. Due to dizziness and head swelling for 10 days, aggravated nausea and vomiting for 1 day, he was re-admitted to the hospital on June 27, 2018. Since then, the patient had stopped taking all oral medications, including icotinib. The blood test results showed that blood creatinine $887.14 \mu \mathrm{mol} / \mathrm{L}$, BUN $51.08 \mathrm{mmol} / \mathrm{L}$, blood potassium $5.9 \mathrm{mmol} / \mathrm{L}$, hemoglobin $58 \mathrm{~g} / \mathrm{L}$, CEA $16.7 \mathrm{ng} / \mathrm{mL}$, PSA $0.063 \mathrm{ng} / \mathrm{mL}$, and arterial blood gas analysis showed $\mathrm{pH}$ 7.34. The results of ultrasonography showed hydronephrosis with bilateral ureteral dilatation, irregular thickening of bladder wall with solid nodules and intraluminal sediment. Diagnosis: renal failure, hydronephrosis, metabolic acidosis, electrolyte disturbance. The patient and his family members refused the treatment of hemofiltration, hemodialysis and nephrostomy. The patient died suddenly at home on July 25, 2018, and his family refused to perform the autopsy. Written
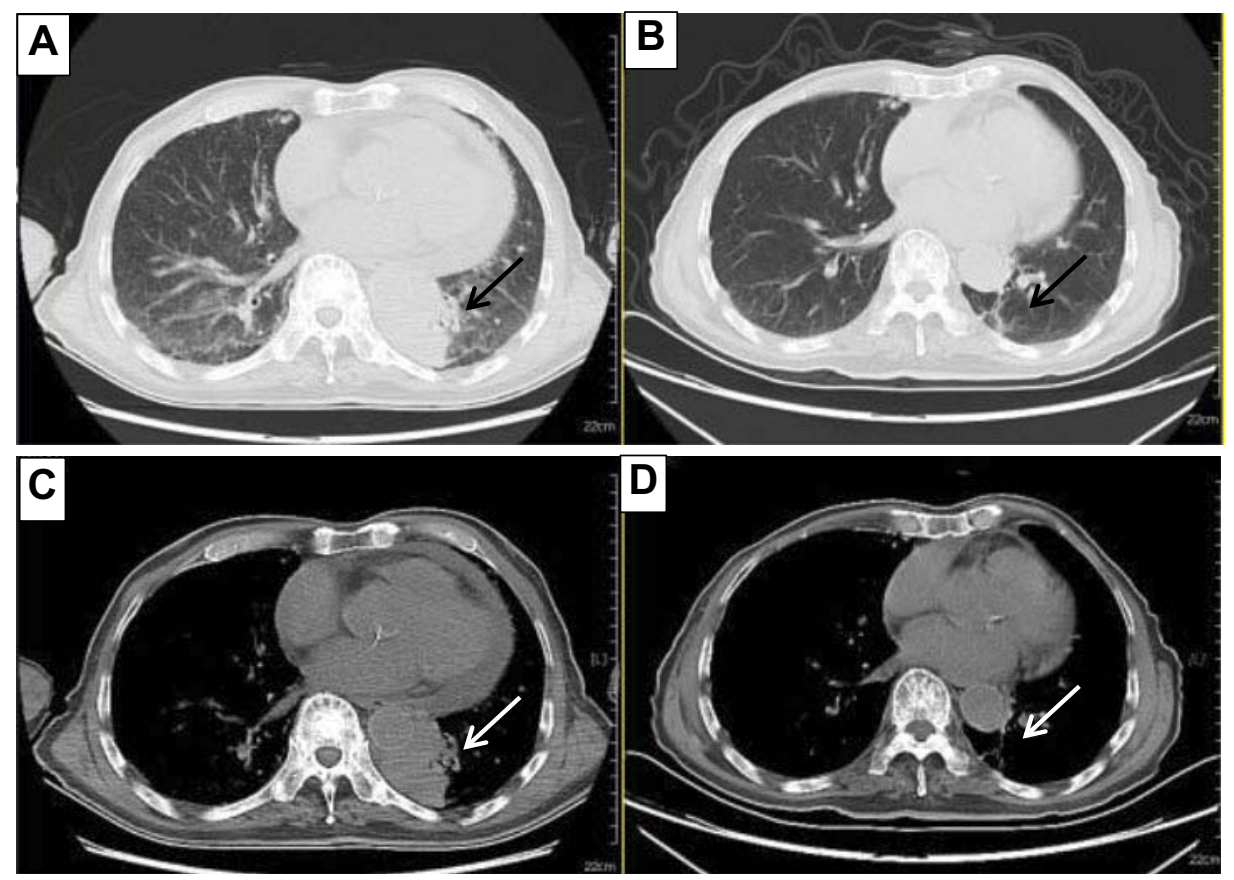

Figure 3 The tumor was compared between lung window and mediastinal window on chest CT. Chest CT showed that the lung tumor size was significantly reduced in January 19, 2017 (B, D) compared with September I, 2016 (A, C). 

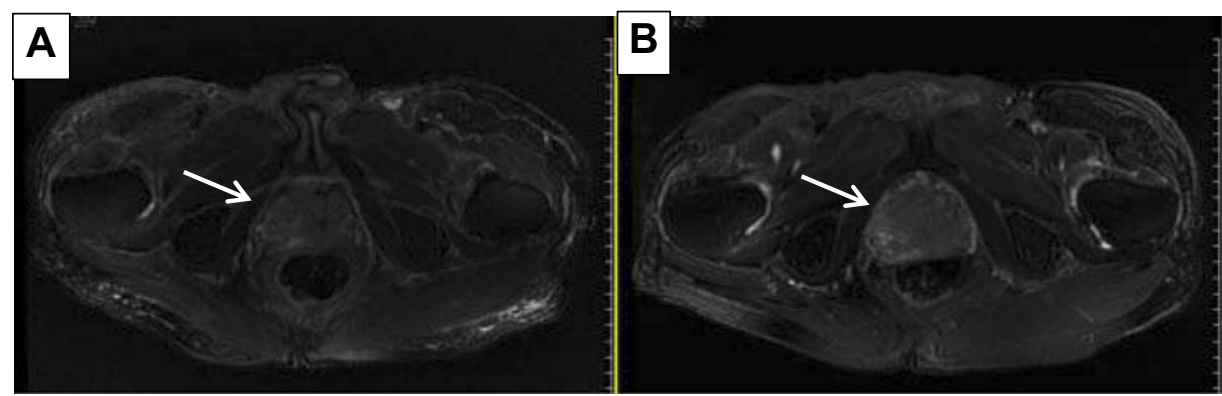

Figure 4 Prostrate MRI examination. Abnormal signal foci in the central region of prostate magnetic resonance imaging in September I, 2016 (A), irregular enlargement of prostate and abnormal signal in April 17, 2017 (B), which was considered as prostate cancer.

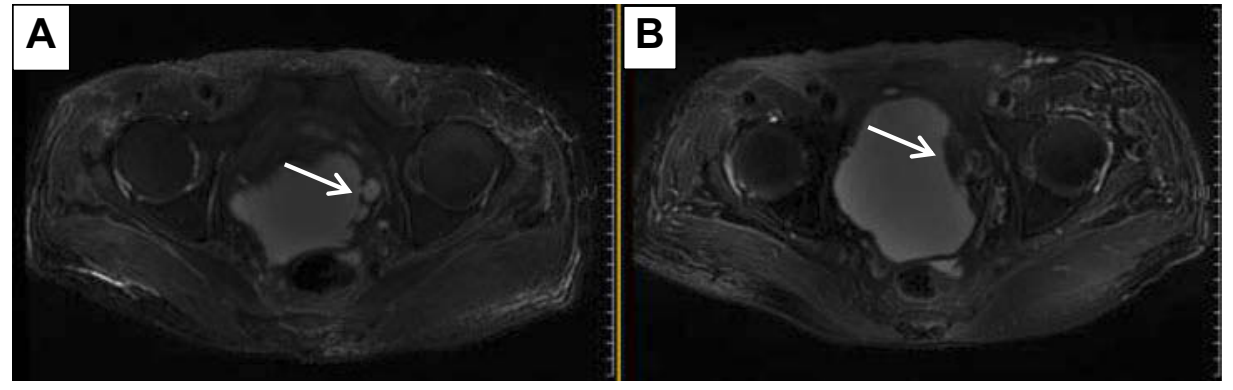

Figure 5 Bladder MRI examination. In September I, 2016 (A) the bladder was poorly filled, with several prominent shadow-like sacs on the left side wall; sacs on the left side wall had grown up to be occupied space in April 17, 2017 (B).
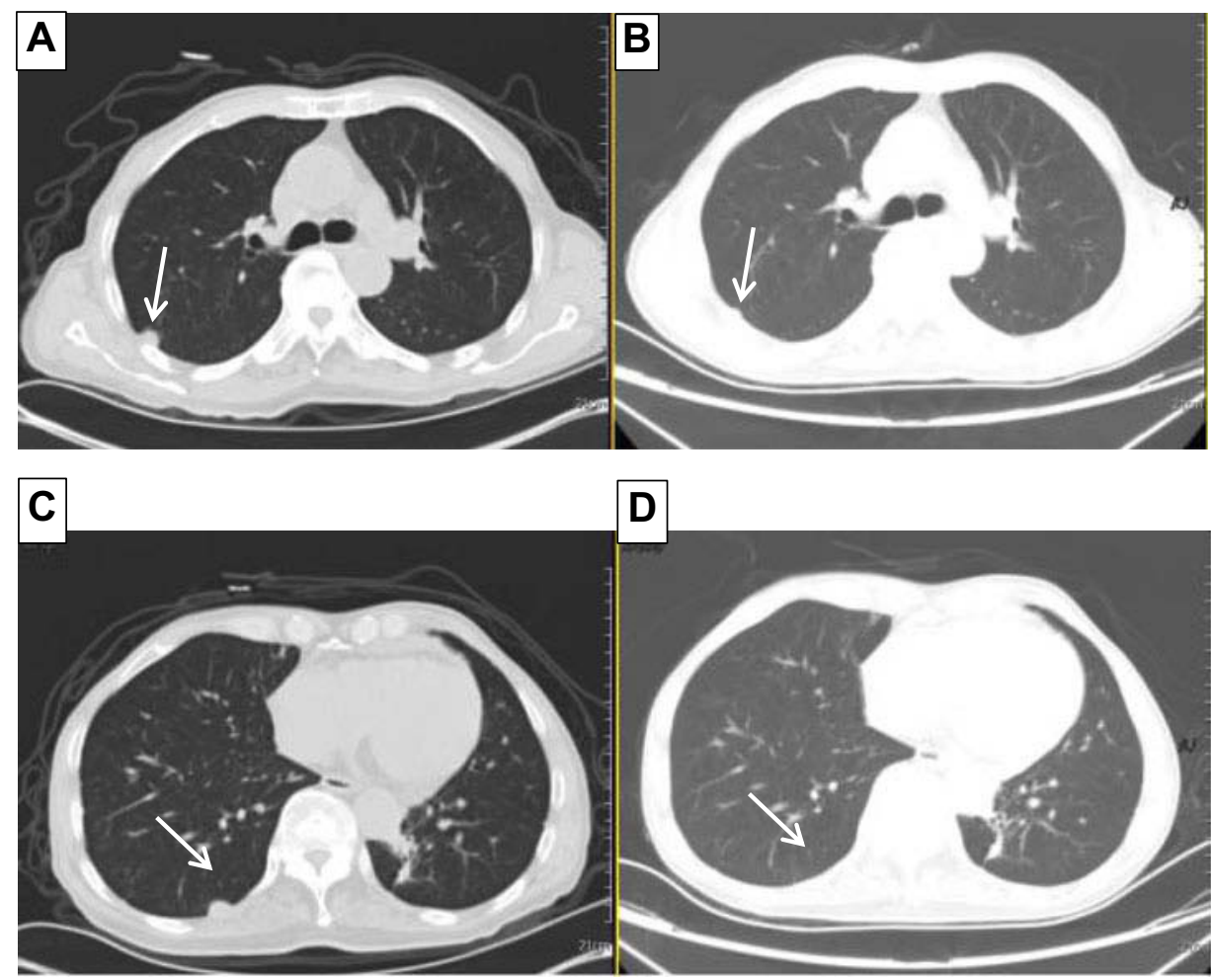

Figure 6 Chest CT. Partial nodules decreased in both lungs (considering the metastasis of prostate cancer in the lungs) in September 3, 2017 (B, D) compared with April 12, 2016 (A, C). 


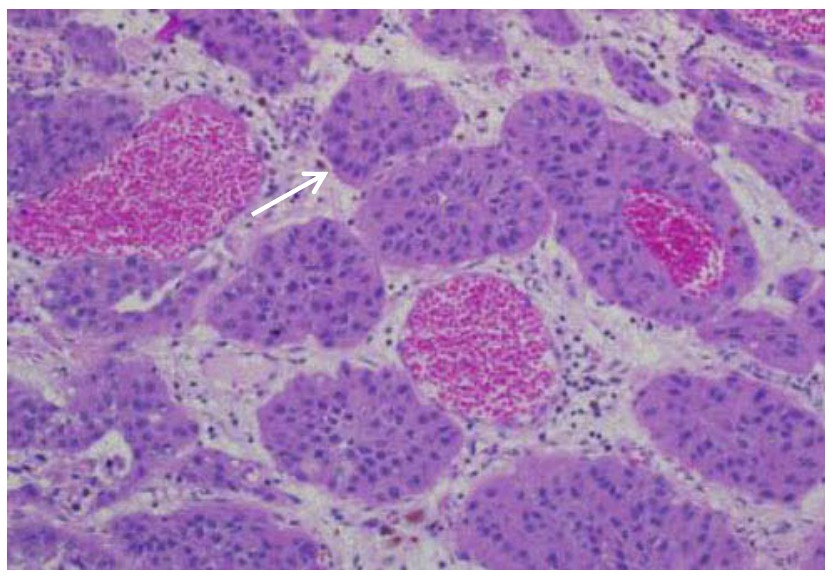

Figure 7 Hematoxylin-eosin-stained $(10 \times 20)$ surgical specimens obtained by transurethral electric resection of bladder lesions. The tumor cells are large with highly atypical nuclei and the histology and immunohistochemical findings suggest invasive urothelial carcinoma. Immunohistochemical results: CK7(+), CK20(-), Ki-67(about $\sim 30 \%+$ ), P53(Scattered+), P63(+), GATA3(+), 34BEI2(+), PSA(-).

informed consent has been provided by the patient's next-of-kin to have the case details and any accompanying images published.

\section{Discussion}

For patients without early screening, most of the time when malignant tumors are found was when patients go to hospital because of obvious symptoms, while most of the symptoms appear in the late stage of malignant tumors. Evidence suggests that genetic disorders and somatic mutations, behavioral influences, lifestyles and comorbidities usually affect the prognosis of patients. ${ }^{2,14,15}$ Studies suggest that age, ethnic background, smoking, alcohol abuse, overweight, gender, family history and previous treatment are risk factors for multiple primary tumors, ${ }^{3}$ and the risk of further primary cancer may increase due to the persistent effects of genetic and behavioral risk factors, and increased diagnostic sensitivity. ${ }^{16}$ According to previous studies, patients with bladder cancer have an increased risk of lung cancer and prostate cancer, ${ }^{17}$ and patients who initially develop bladder, prostate cancer are more likely to develop a second malignancy. ${ }^{3}$ In Levi et al's study on second primary cancer, the most common sites of the first tumor include prostate, bladder/ureter squamous cell carcinoma, etc., and the most common sites of the second tumor include lung and prostate. ${ }^{18}$ Different variations of CDKN2B-AS1 loci are known to be associated with lung adenocarcinoma and prostate cancer. ${ }^{19}$ The 10 most common subsequent primary cancers after lung and bronchus cancer include prostate cancer and urinary bladder cancer. ${ }^{20}$ As high as $5.0 \%$ of the patients with lung cancer were patients with multiple malignant tumors. As the second malignant tumor, lung cancer develops more frequently in patients with multiple malignant tumors. Synchronous cancers are more pronounced in old age than metachronous cancers. ${ }^{21}$

Table 1 summarizes the cases with synchronous triple primary malignancies including lung cancer. As can be easily seen, triple synchronous primary lung cancer is the most frequently reported.

In patients with synchronous multiple primaries, it should be noted that in most cases, the treatment recommended by the doctor is personal decision, not general treatment recommendation, and these treatments are not based on prospective experimental evidence, but on "realistic" examples of challenging clinical situations. ${ }^{1}$

The literature on the phenomenon of synchronous triple primary malignancies: lung cancer, prostate cancer and bladder cancer in a single patient are reviewed which included a PubMed database search from 1980 to December 2017 of reported cases in English. The search was performed by using various combinations of searching keywords involving "(synchronous triple primary malignancies OR three simultaneous cancers OR multiple concurrent cancers OR multiple primary carcinomas) AND (lung carcinoma OR lung cancer OR bronchiogenic cancer OR bronchiogenic carcinoma OR lung adenocarcinoma) AND (prostatic carcinoma OR prostatic cancer OR prostate carcinoma) AND (carcinoma of urinary bladder OR bladder cancer OR bladder carcinoma)". There were only two case reports referring to patients with these three primary malignancies. In the case reported by Koutsopoulos et al in 2005, the first tumor was a urinary bladder transitional cell carcinoma, which was followed by metachronous prostate adenocarcinoma and then by small cell lung carcinoma which was revealed 7 months later. Bladder cancer and prostate cancer had undergone surgery, while small cell lung cancer had undergone chemotherapy, and the patient died of the toxicity of the first chemotherapy. ${ }^{22}$ The other case reported by Otrock et al also in 2005 showed that the patient was first diagnosed with lung adenosquamous carcinoma and underwent pneumonectomy, adjuvant chemotherapy and radiotherapy. Eleven years later, he was diagnosed with bladder cancer and prostate cancer and underwent surgery. One and a half years after that he was diagnosed with breast cancer and received chemotherapy. One year later, he died of septic shock. ${ }^{23}$ Our case is the first one of clinical diagnosis and 


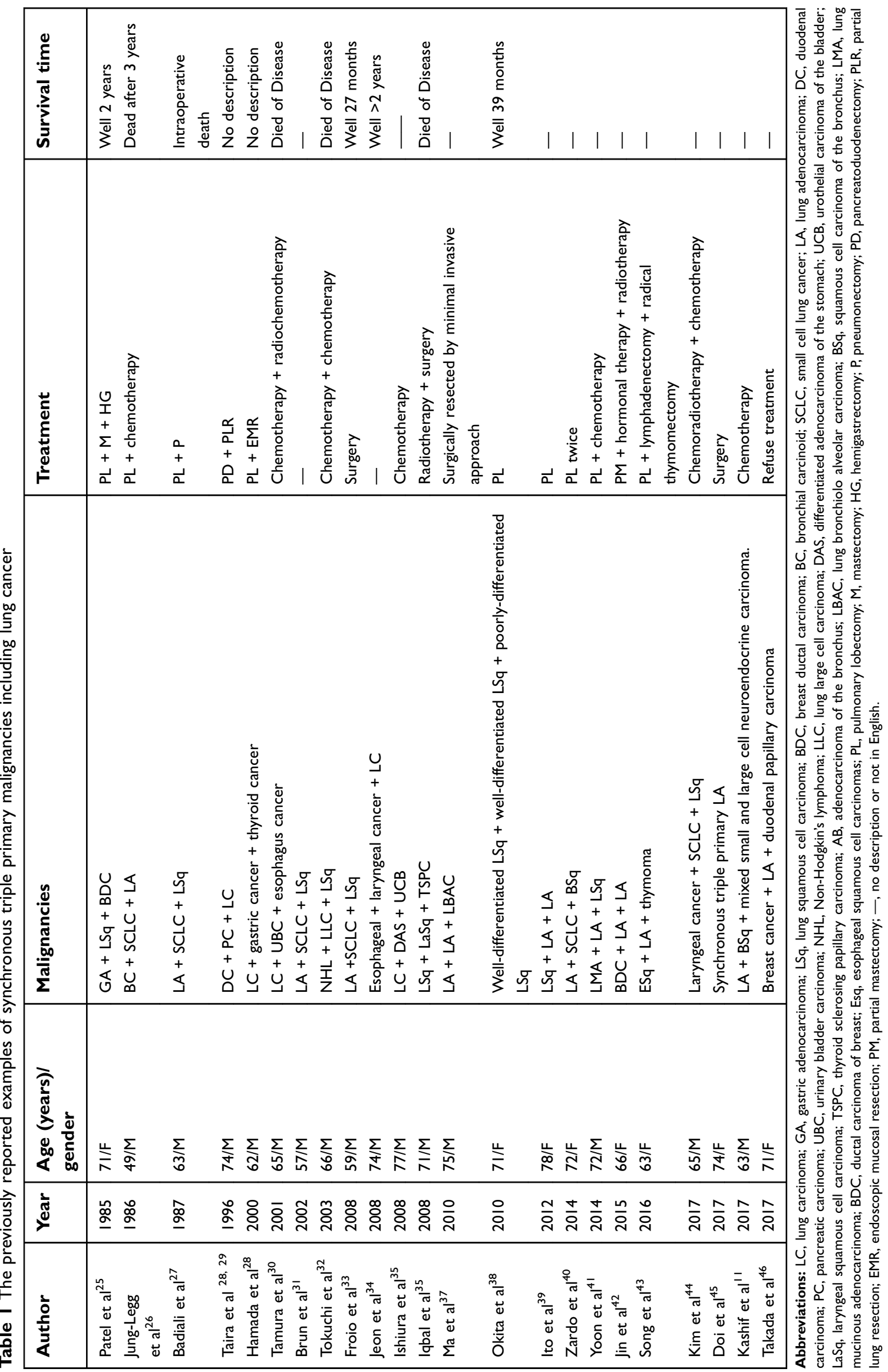


treatment on how doctors should deal with the three primary malignancies involving separate organs of lung cancer, prostate cancer and bladder cancer occurring in the same patient at the same time.

For this patient, the three tumors were clearly demonstrated by imaging examination at the time of initial diagnosis and were present at the same time. The presence of bone metastases suggests that the disease is at an advanced stage. The diagnosis of lung cancer and bladder cancer was made after obtaining pathological samples. The diagnosis of prostate cancer was based on the patient's symptoms, imaging characteristics and PSA test results. After hormonal treatment, the patient's symptoms improved, the PSA value decreased and some of the lung nodes considered as metastases of prostate cancer decreased significantly, thus further clarifying the diagnosis of prostate cancer.

Subsequently, targeted therapy for lung cancer eliminates patients' fear of cancer therapy and strengthens patients' confidence in treatment, because in patients' mind, cancer treatment, whether chemotherapy or radiotherapy, will have painful digestive tract symptoms or fatigue, hair loss, etc., not only is targeted therapy less painful, simpler to administer, but it is also very effective, and its benefits exceed expectations too much. All of these made it easier for doctors to make decisions about the next treatment for patients. The effect of prostate cancer treatment is in line with doctors' expectations as well as patients' requirements and wishes: good results, less suffering. The treatment of bladder cancer causes tremendous suffering: surgery, postoperative bleeding, infection, relapse, severe physical wastage until cachexia. Cachexia is also a common manifestation of advanced cancer in many patients. There is nothing we could do to see the patient's difficulties at that time. However, the family members of the patients were satisfied with the treatment they received throughout the course of the disease.

Diagnostic stage is another important prognostic factor. As the disease progresses, the decline in survival indicates the importance of screening and early detection. ${ }^{24}$ For synchronous multiple primary tumors, whether from diagnosis to treatment, it is more complex than single or metachronous multiple tumors, which brings more suffering to patients. Although all three types of tumors were present at the time of admission, it cannot be ruled out that the three types of tumors did not initially grow at the same time, especially the bladder cancer that was finally treated. If it could be detected and treated at an early stage, the prognosis of the patient will be different.
In all aspects of clinical work, doctors first treat the most painful and life-threatening parts of patients, and the principle is the same in the case of multiple cancers. No matter what the diagnostic results are, clinicians should treat patients with a scientific attitude of respecting patients' wishes and on the premise of minimizing patients' pain, not just as scientific research. From this point of view, targeted therapy really reflects the progress of modern science and brings good news to patients, especially cancer patients. The slight side effects of drugs also make it more feasible for doctors to make a definite diagnosis by observing the reaction of the disease to drugs after direct medication, which can avoid the pain of invasive examinations and be more acceptable to patients.

\section{Disclosure}

The authors report no conflicts of interest in this work.

\section{References}

1. Vogt A, Schmid S, Heinimann K, et al. Multiple primary tumours: challenges and approaches, a review. ESMO Open. 2017;2:e000172. doi:10.1136/esmoopen-2017-000172

2. American Cancer Society. Cancer Facts \& Gures 2016. Atlanta: American Cancer Society; 2016.

3. Amer MH. Multiple neoplasms, single primaries, and patient survival. Cancer Manag Res. 2014;6:119-134. doi:10.2147/CMAR

4. Soerjomataram I, Coebergh JW. Epidemiology of multiple primary cancers. Methods Mol Biol. 2009;471:85-105.

5. Soerjomataram I, Louwman WJ, de Vries E, Lemmens VE, Klokman WJ, Coebergh JW. Primary malignancy after primary female breast cancer in the South of The Netherlands, 1972-2001. Breast Cancer Res Treat. 2005;93(1):91-95. doi:10.1007/s10549005-5198-3

6. Thomas A, Mailankody S, Korde N, Kristinsson SY, Turesson I, Landgren $\mathrm{O}$. Second malignancies after multiple myeloma: from 1960s to 2010s. Blood. 2012;119(12):2731-2737. doi:10.1182/ blood-2011-10-388512

7. Liu L, de Vries E, Louwman M, et al. Prevalenceofmultiplemalignancies in The Netherlands in 2007. Int $J$ Cancer. 2011;128(7):1659-1667. doi:10.1002/ijc. 25577

8. Friedrich RE. Primary and second primary cancer in 649 patients with malignancies of the maxillofacial region. Anticancer Res. 2007;27(4A):1805-1818.

9. Aziz TM, Saad RA, Glasser J, Jilaihawi AN, Prakash D. The management of second primary lung cancers. A single centre experience in 15 years. Eur J Cardiothorac Surg. 2002;21(3):527-533.

10. Kurzyński M, Mituś J, Kołodziej-Rzepa M, Sas-Korczyńska B. Bilateral synchronous breast cancer developed as metachronous malignancy after therapy of other primaries. Ginekol Pol. 2018;89 (5):235-239. doi:10.5603/GP.a2018.0041

11. Kashif M, Ayyadurai P, Thanha L, Khaja M. Triple synchronous primary lung cancer: a case report and review of the literature. J Med Case Rep. 2017;11(1):245. doi:10.1186/s13256-017-14 $10-4$

12. Xue X, Xue Q, Wang N, et al. Early clinical diagnosis of synchronous multiple primary lung cancer. Oncol Lett. 2012;3(1):234-237. doi:10.3892/ol.2011.444 
13. Seegobin K, Staggs E, Khawaja R, et al. Pilot study on the occurrence of multiple cancers following cancer-related therapy at the University of Florida, Jacksonville (2011-2016). J Investig Med. 2018;66 (7):1050-1054. Epub 2018 Jun 6. doi:10.1136/jim-2018-000772

14. Berrington de Gonzalez A, Curtis RE, Kry SF, et al. Proportion of second cancers attributable to radiotherapy treatment in adults: a cohort study in the US SEER cancer registries. Lancet Oncol. 2011;12:353-360. doi:10.1016/S1470-2045(11)70061-4

15. Morton LM, Onel K, Curtis RE, Hungate EA, Armstrong GT. The rising incidence of second cancers: patterns of occurrence and identi cation of risk factors for children and adults. Am Soc Clin Oncol Educ Book. 2014;34:e57-e67. doi:10.14694/EdBook_AM.2014.34.e57

16. Curtis RE, Freedman DM, Ron E, et al. New Malignancies among Cancer Survivors: SEER Cancer Registries, 1973-2000. Bethesda, MD: National Cancer Institute; 2006. NIH Publ. No. 05-5302.

17. Coyte A, Morrison DS, Philip M. Second primary cancer risk - the impact of applying different definitions of multiple primaries: results from a retrospective population-based cancer registry study. Coyte et al. BMC Cancer. 2014;14:272. doi:10.1186/1471-2407-14-272

18. Levi F, Randimbison L, Rafael BM, Manuela MC, La Vecchia C. Second primary cancers in the vaud and neuchâtel cancer registries. Eur J Cancer Prev. 2015;24(2):150-154. doi:10.1097/CEJ.000000 0000000085

19. Fehringer G, Kraft P, Pharoah PD, et al. Cross-cancer genome-wide analysis of lung, ovary, breast, prostate, and colorectal cancer reveals novel pleiotropic associations. Cancer Res. 2016;76(17):5103-5114. Epub 2016 Apr 20. doi:10.1158/0008-5472.CAN-15-2980

20. Mao R, Chen T, Zhou F, et al. The burdens of lung cancer involved multiple primary cancers and its occurring patterns-SEER analysis between 1973 and 2006. Sci Rep. 2017;7(1):6451. doi:10.1038/ s41598-017-06763-2

21. Romaszko A, Świetlik E, Doboszyńska A, Szpruch P, Luks J. Lung cancer multiple neoplasms: a retrospective analysis. Adv Exp Med Biol. 2016;911:53-58. doi:10.1007/5584_2016_224

22. Koutsopoulos AV, Dambaki KI, Datseris G, Giannikaki E, Froudarakis M, Stathopoulos E. A novel combination of multiple primary carcinomas: urinary bladder transitional cell carcinoma, prostate adenocarcinoma and small cell lung carcinoma-report of a case and review of the literature. World J Surg Oncol. 2005;26 (3):51. doi:10.1186/1477-7819-3-51

23. Otrock ZK, Mahfouz RA, Salem ZM. Four primary tumors of lung, bladder, prostate, and breast in a male patient. South Med J. 2005;98 (9):946-949. doi:10.1097/01.smj.0000173086.37625.e2

24. Hayat MJ, Howlader N, Reichman ME, Edwards BK. Cancer statistics, trends, and multiple primary cancer analyses from the Surveillance, Epidemiology, and End Results (SEER) program. Oncologist. 2007;12(1):20-37. doi:10.1634/theoncologist.12-1-20

25. Patel S, Alfonso AE, Landis J, Suarez J. Three synchronous multiorgan primary cancers. All stage I. Arch Surg. 1985;120(10): 1182-1184.

26. Jung-Legg Y, McGowan SE, Sweeney KG, Zitzman JL, Pugatch RD. Synchronous triple malignant tumors of the lung. A case report of bronchial carcinoid, small cell carcinoma, and adenocarcinoma of the right lung. Am J Clin Pathol. 1986;85(1):96-101.

27. Badiali P, Alloisio M, Lombardi L. Synchronous triple carcinoma of the lung in one patient. Tumori. 1987;73(5):525-529.

28. Hamada Y, Takise A, Uno D, Itoh H, Ichikawa H, Morishta Y. Synchronous primary triple cancers including the lung, stomach, and thyroid: a case report. Kyobu Geka. 2000;53(2):101-105.

29. Taira K, Shiraishi M, Sunagawa H, Takushi Y, Shimoji H, Tomita S, Honma K, Muto Y. Resection of triple synchronous cancers: a case report. Hepatogastroenterology. 1999;46(25):199-203.
30. Tamura K, Inoue K, Fukata S, Kamada M, Shuin T. Small cell carcinoma of the urinary bladder with synchronous esophageal cancer and incidental lung cancer: a case report. Hinyokika Kiyo. 2001;47 (4):273-276.

31. Brun S, Paparelli C, Sinnona N, Venuti VM. Synchronous lung cancer; clinical case of triple lung carcinoma. G Chir. 2002;23 (1-2):43-44

32. Tokuchi Y, Kamachi M, Harada M, et al. Synchronous triple lung cancers after treatment for non-Hodgkin's lymphoma: metachronous quadruple cancers. Intern Med. 2003;42(10):1031-1034.

33. Froio E, D’Adda T, Fellegara G, Ampollini L, Carbognani P, Rindi G. Three different synchronous primary lung tumours: a case report with extensive genetic analysis and review of the literature. Lung Cancer. 2008;59(3):395-402. Epub 2007 Aug 20. doi:10.1016/ j.lungcan.2007.07.007

34. Jeon SY, Ahn SH, Kim CH, Lim SM, Koh JS, Lee JC. Esophageal and laryngeal cancer incidentally found on $[18 \mathrm{~F}]$ fluorodeoxyglucose positron emission tomography/computed tomography during the staging workup for lung cancer. Clin Lung Cancer. 2008;9(4):230-231. doi:10.3816/CLC.2008.n.035

35. Ishiura Y, Yamamoto H, Terasaki Y, et al. A case of synchronous triple cancer involving lung, stomach and bladder, responding to combination chemotherapy of S-1 and cisplatin. Gan To Kagaku Ryoho. 2008;35(8):1395-1397.

36. Iqbal FR, Sani A, Gendeh BS, Aireen I. Triple primary cancers of the larynx, lung and thyroid presenting in one patient. Med J Malaysia. 2008;63(5):417-418

37. Ma ES1, Cheng PN, Wong CL, Yim AP. Synchronous primary lung cancer and epidermal growth factor receptor mutation. Ann Thorac Surg. 2010;90(3):e38-9. doi:10.1016/j.athoracsur.2010.06.042

38. Okita R, Shimizu K, Mimura T, Miyata Y, Okada M, Arihiro K. Suggestive synchronous triple squamous cell carcinoma of the lung in the same lobe. Gen Thorac Cardiovasc Surg. 2010;58(8):427-430. Epub 2010 Aug 12. doi:10.1007/s11748-009-0476-3

39. Ito T, Kawasaki N, Kinoshita M, Inada H, Tei S, Ikeda N. Triple synchronous primary lung carcinomas in the same lobe; report of a case. Kyobu Geka. 2012;65(9):832-835.

40. Zardo P, Krüer T, Schiffmann S, Freermann S, Fischer S. Triple synchronous primary lung cancer. Asian Cardiovasc Thorac Ann. 2014;22(7):865-868. Epub 2013 Oct 17. doi:10.1177/0218 492313495550

41. Yoon HJ, Lee HY, Han J, Choi YL. Synchronous triple primary lung cancers: a case report. Korean J Radiol. 2014;15(5):646-650. Epub 2014 Sep 12. doi:10.3348/kjr.2014.15.5.646

42. Jin CJ, Mei X, Falkson CB. A case of synchronous breast and bilateral lung cancers: literature review and considerations for radiation treatment planning. BJR Case Rep. 2015;3(1):20150464. eCollection 2017. doi:10.1259/bjrcr.20150464

43. Song X, Shen H, Li J, Wang F. Minimally invasive resection of synchronous triple primary tumors of the esophagus, lung, and thymus: A case report. Int J Surg Case Rep. 2016;29:59-62. Epub 2016 Oct 23. doi:10.1016/j.ijscr.2016.10.048

44. Kim EK, Kim JY, Kim BM, Lim SN. Multiple primary malignancies of laryngeal cancer, small cell lung cancer and squamous cell lung cancer in a patient: how to approach MPMs. BMJ Case Rep. 2017; pii:bcr2016216305. doi:10.1136/bcr-2016-216305

45. Doi T, Sakamoto T. Synchronous triple primary lung adenocarcinomas, one of which showing a thin-walled cavity nodule; report of a case. Kyobu Geka. 2017;70(3):227-230.

46. Takada K, Kashiwagi S, Amano R, et al. Case of synchronous triple cancer of the breast, duodenal and lung. Gan To Kagaku Ryoho. 2017;44(12):1074-1076. 


\section{Publish your work in this journal}

OncoTargets and Therapy is an international, peer-reviewed, open access journal focusing on the pathological basis of all cancers, potential targets for therapy and treatment protocols employed to improve the management of cancer patients. The journal also focuses on the impact of management programs and new therapeutic agents and protocols on patient perspectives such as quality of life, adherence and satisfaction. The manuscript management system is completely online and includes a very quick and fair peer-review system, which is all easy to use. Visit http://www.dovepress.com/ testimonials.php to read real quotes from published authors.

Submit your manuscript here: https://www.dovepress.com/oncotargets-and-therapy-journal 